\title{
A arquitetura hospitalar pós pandemia: adequando hospitais aos novos tempos
}

\author{
Elza Maria Alves Costeira \\ Arquiteta DSc. (Espaço Saúde/ PROARQ/FAU/UFRJ) \\ Diretora de Relações Institucionais Américas (ABDEH) \\ 凶 ecosteira@uol.com.br
}

A ocorrência de epidemias e seu aparecimento recorrente, na história da trajetória do homo sapiens no nosso planeta, evidencia a necessidade em criar mecanismos de proteção das populações frente ao receio do surgimento de novos agravos e sucessivas ondas de reinfestação desses males, em grande número de habitantes dos mais diversos países.

Após as últimas ocorrências no surgimento de novas cepas da atual SARS-CoV-2, e os índices de infecção das pessoas, que continuam instáveis e sensíveis a variações as mais diversas, de locais, faixas etárias e morbimortalidade de suas ocorrências, os cientistas se debruçam com justificada urgência, em pesquisas para o estabelecimento de vacinas, remédios e bloqueios na disseminação das infestações e suas graves consequências, em todo o mundo.

Esses tempos de dificuldades e temores nos levam a reflexões sobre o estado de agressão onde chegamos, em relação ao meio ambiente pois fica claro que o aparecimento destes problemas de saúde reflete o que tem enfrentado nosso planeta, a partir de ações negligentes no uso de fontes não renováveis de combustíveis e com o aquecimento global fruto da aceleração do efeito estufa, causado pelas práticas agressivas e pelas ações de desequilíbrio do habitat da vida selvagem, em busca de um desenvolvimento nem sempre sustentável e de potencial nocivo à natureza.

Sem nenhuma dúvida, a ciência aponta para uma profunda reflexão sobre a inovação das práticas de geração de energia, procurando acelerar as pesquisas sobre novas fontes energéticas, a serem aplicadas no desenvolvimento das nações, no uso de recursos alternativos e renováveis, conformando um meio ambiente mais justo e protegido de agressões geradoras de desequilíbrios à biota, animais, espécies raras e, quem sabe, de doenças que aparecem frente a quaisquer desequilíbrios indesejados no seu habitat. 
Nesse sentido, a pesquisa sobre a transformação de usos e de recursos estruturantes da indústria da construção civil, vem se tornando peça-chave para repensar a consolidação de prédios que sejam mais conectados com a proteção ambiental, gerando ganhos para os usuários e para o meio ambiente onde se inserem. O Hospital do Futuro tem que estar preparado para que sua Arquitetura seja capaz de atender ao desenvolvimento da ciência e tecnologia médica e às emergências de catástrofes, pandemias e desastres naturais. Ele deve ser:

\section{MODULAR, FLEXÍVEL E EXPANSIVEL}

A concepção dos projetos hospitalares deverá, mais do que nunca, aplicar conceitos de coordenação modular para tornar seus edifícios flexíveis e adaptáveis a quaisquer eventos adversos, fora dos padrões de sua expectativa de funcionamento. A atual pandemia vivenciada por todos, sobrecarregou os sistemas de saúde e exigiu que leitos intensivos fossem disponibilizados em maior número do que as previsões e estudos anteriores de epidemiologia e percentual de adoecimento da população. Os parâmetros usuais de proporção de número de leitos de cuidados intensivos, e de alguns recursos energéticos, foram exigidos em número maior e de modo mais urgente na adaptação de espaços de internação.

Ao se retomar as condições usuais de funcionamento, com demandas já normalizadas e parâmetros usualmente empregados para cuidados de saúde, os ambientes críticos e semicríticos vão ter que readaptar suas condições à necessidades semelhantes às da pré pandemia, evidenciando a necessidade da flexibilidade de sua ambiência e recursos energéticos. Certamente a coordenação modular e a previsão de pontos de gases e de força deverão ser redimensionados para atender a quaisquer urgências na demanda de seu funcionamento.

Figura 1.: Unidades de Terapia Intensiva modulares e transportáveis, Argentina. 


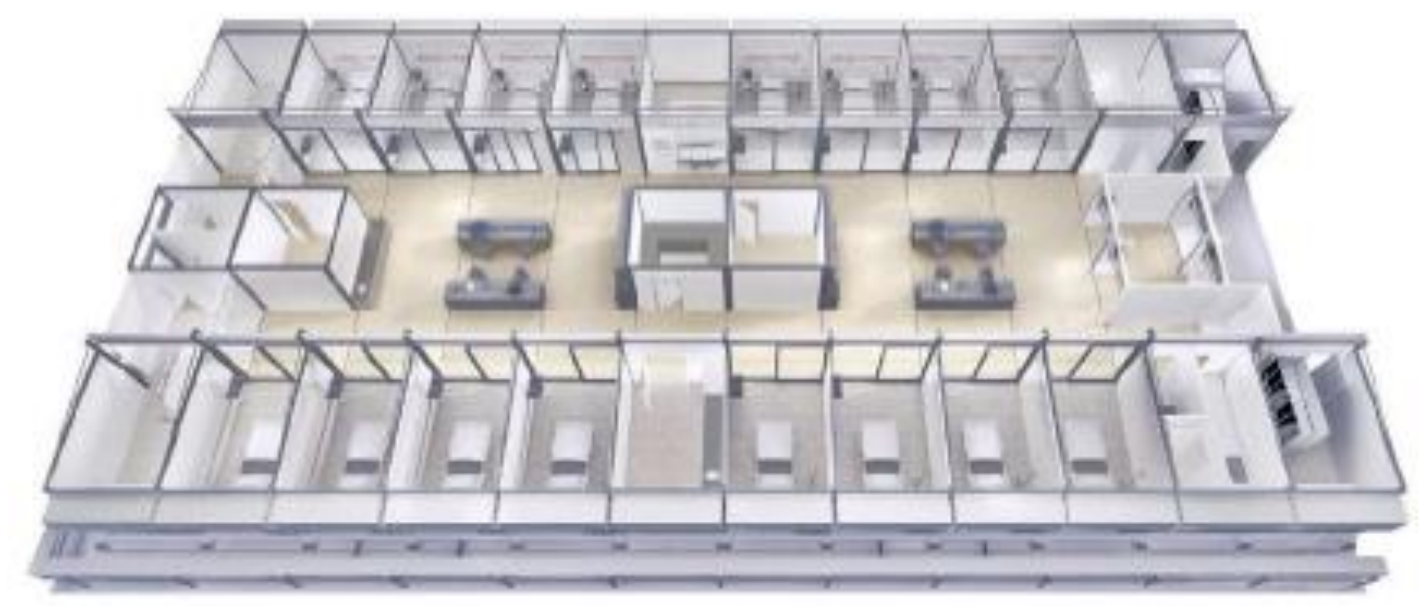

Fonte: AADAIH, Anuário 2020, Argentina, 2020.

\section{VERDE, AMIGO DO MEIO AMBIENTE, SUSTENTÁVEL}

A aplicação de sistemas de geração de energia alternativa, o estudo do esgotamento de efluentes, a previsão do uso de envoltórias economizadoras de energia para climatização, o uso de captação de águas da chuva para reuso, telhados verdes e, de modo enfático, a implantação inteligente dos prédios utilizando a iluminação e a ventilação natural nas áreas possíveis de serem naturalmente ventiladas, serão importantes para a busca de uma construção e uso de hospitais mais inseridos idealmente em seu entorno.

Um retorno aos ambientes naturalmente ventilados- ambientes não críticos- poderá representar um saudável partido, especialmente se enfatizamos os benefícios da diluição de bactérias e vírus quando grandemente diluídos e renovados na sua dispersão em ambientes plenamente ventilados e, se possível, fartamente iluminados pela luz diurna.

Esta premissa no projetar afasta cada vez mais os hospitais da conhecida "síndrome dos edifícios doentes". Certamente a inspiração dos tempos das enfermarias Nightingale deverá ser revisitada e redirecionada para atender a todas as exigências da atualidade médica 
sem abrir mão do ar puro e do sol nos ambientes, com ênfase nas áreas de internação e de repouso de funcionários.

Figura 2.: O Hospital do Aeroporto de Tianjin, na China.

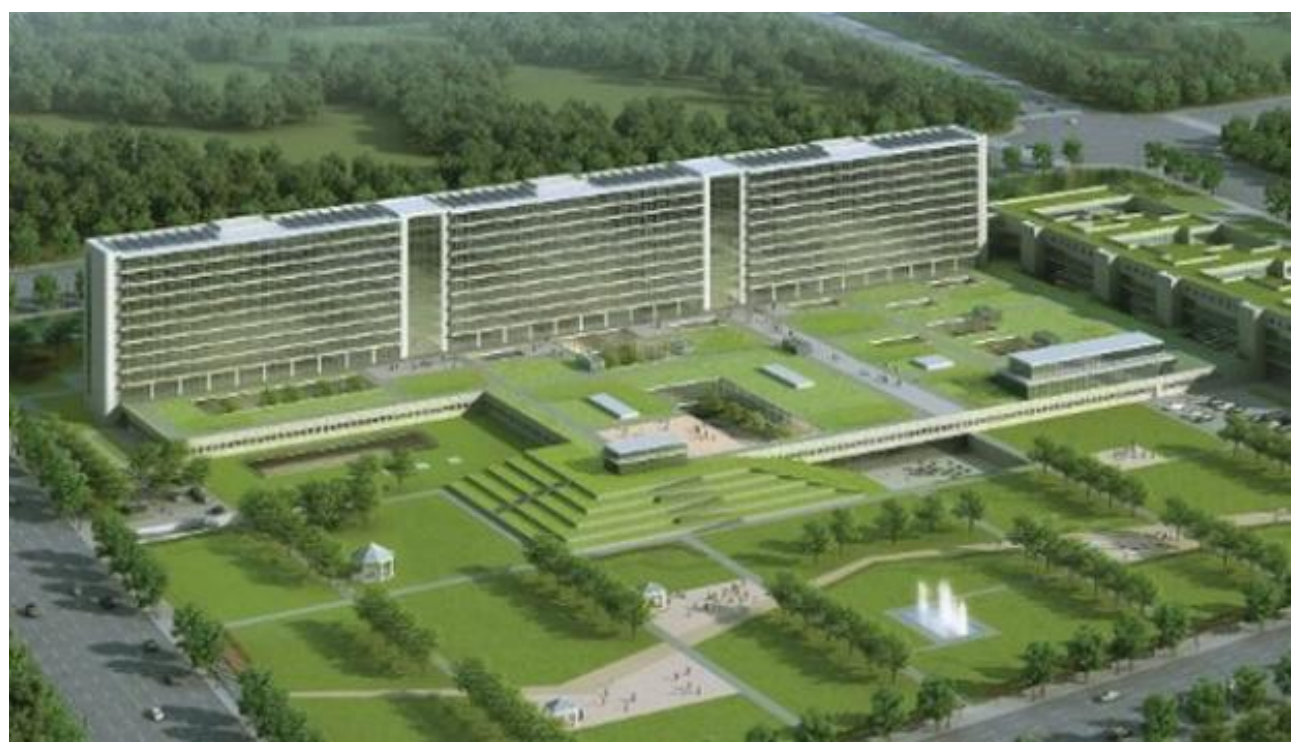

Fonte: https://ecotelhado.com/um-hospital-aeroporto-ligado-na-sustentabilidade/ Acesso em $15 / 06 / 2021$.

\section{CONECTADO À REDE MUNDIAL, À CIÊNCIA E À PESQUISA}

Em se tratando dos tempos da nova revolução tecnológica, cada vez mais as trocas e discussões de casos médicos serão possíveis, em ligação com todos os grandes centros de tratamento e de pesquisas em todo o mundo. A ciência médica, a robótica, as cirurgias e tratamentos que disponibilizam técnicas como realidade virtual, exames pouco invasivos, imagenologia de ponta e a possibilidade da discussão de casos à distância, devem ter garantido o acesso à a internet das coisas e sua disponibilidade largamente facilitada nos ambientes de diagnóstico e terapia, conectando centros médicos de excelência, onde quer que se encontrem.

Ainda, as pesquisas com células tronco, as impressoras do futuro, que manejarão matéria prima de bancos de tecidos e de células, as pesquisas com diagnóstico à distância a partir de wearables e acessórios portáteis ligados a tablets e celulares, as cirurgias 
minimamente invasivas vão ter suas necessidades de facilitação de conexão com interlocutores distantes.

Essas questões vão exigir construções hospitalares totalmente conectadas, dispondo de redes e cabos em profusão para atender com excelência os agravos e, mesmo, seu acompanhamento pós procedimentos, os follow up dos atendimentos.

Figura 3: Sala Híbrida do Instituto Estadual do Cérebro Paulo Niemeyer.

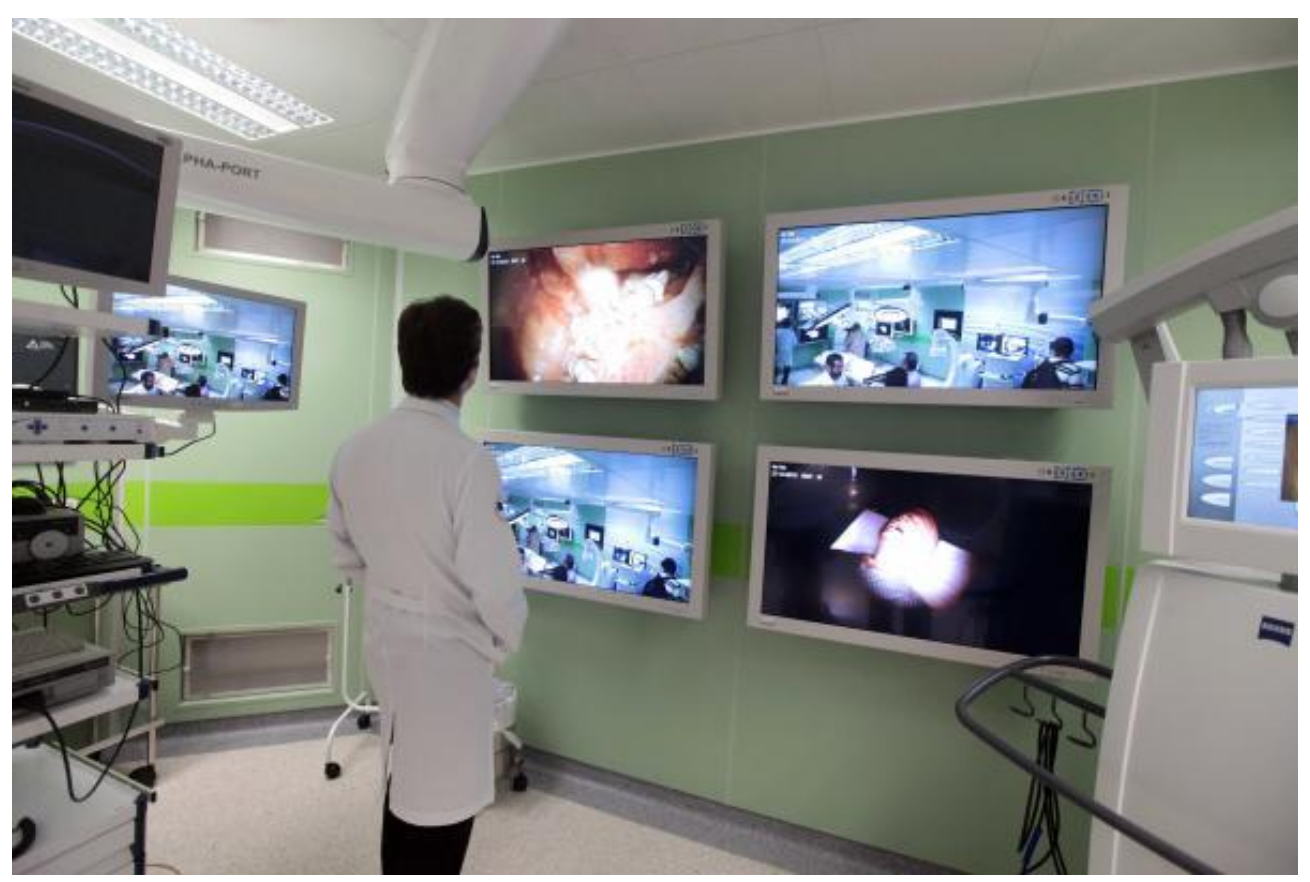

Fonte: http://www.radiologiarj.com.br Acesso em 15/06/2021.

\section{HUMANIZADO PARA PACIENTES, ACOMPANHANTES E FUNCIONÁRIOS}

O Hospital do Futuro vai ter que repensar todo o conceito de humanização e acolhimento aprimorando a experiência do paciente e o conforto das equipes de trabalho. A presença da natureza, do acompanhante, do apoio personalizado da equipe, de distrações positivas e de acesso, ainda que apenas visual, ao entorno, usufruindo da luz e ventilação naturais, onde e quando possível, são elementos que apressam a cura e amenizam a estadia hospitalar. ] 
Figura 4.: Maggie's Center, centro oncológico, projeto de Foster+Partners, Manchester, Inglaterra, 2016.

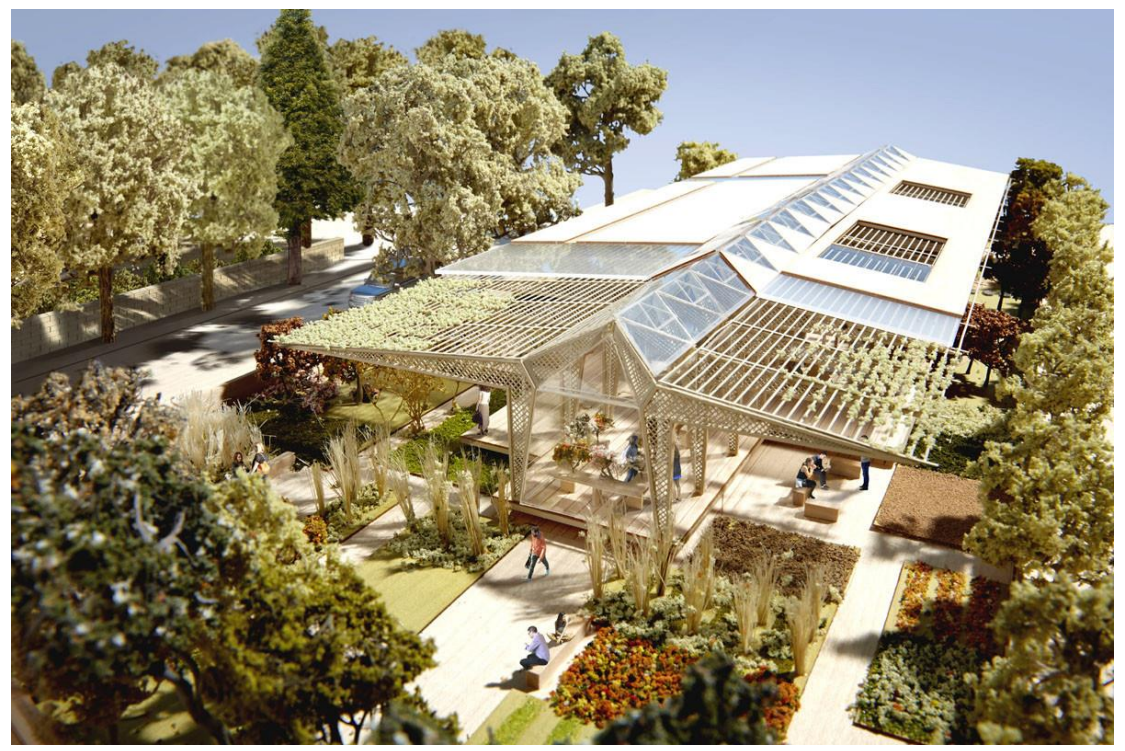

Fonte: https://www.archdaily.com.br/br/786620/centro-de-tratamento-de-cancer-manchesterfoster-plus-partners Acesso em 15/06/2021.

O Hospital do Futuro terá que ser pensado para abrigar pacientes e equipes de trabalho, e seu aparato tecnológico, com mais consciência do que seja a disponibilização de espaços saudáveis e construindo um entorno mais justo e equilibrado para todos que, ao buscarem seus serviços, possam testemunhar e participar de relações mais humanas e sustentáveis para com o meio ambiente e a qualidade de vida. 
A arquitetura hospitalar pós pandemia:

adequando hospitais aos novos tempos

\section{PARA LER MAIS SOBRE O ASSUNTO:}

AADAIH, Associación Argentina de Arquitectura e Ingenieria Hospitalaria. Anuário 2020, edición especial digital. ISSN- 2344- 9993. Buenos Aires, Argentina, 2020.

ALMEIDA, Fernando. Os desafios da sustentabilidade uma ruptura urgente Rio de Janeiro Elsevier, 2007

ANTUNES, Thais. 5 Exemplos de sustentabilidade hospitalar na prática, in Helioprint Disponível em https://helioprint.com.br/blog/sustentabilidade-hospitalar/ Acesso em mai, 2021

GEHL, Jan. Cidades para Pessoas Trad Anita Di Marco $3^{\text {a }}$ ed São Paulo, Ed Perspectiva, 2015

OXYMED. Hospital Sustentável Blog Disponível em https://oxymed.com.br/oxymed-hospital-sustentavel/ / Acesso em mai, 2021

SAUNDERS, Lucy. Healthy Cities PPS presentation Disponível em https://londonlivingstreets.files.wordpress.com/2018/04/20180312-lucy-saunders-healthy-streets-check-feb2018.pdf Acesso em mai, 2021

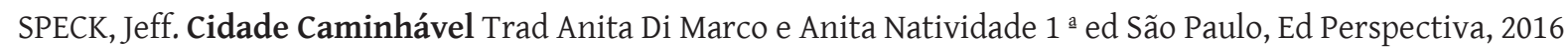

UDVARI, Stefan Cunha. A História e suas Epidemias; a convivência do homem com os micro-organismos. Ed SENAC Rio, Editora SENAC São Paulo, Rio de Janeiro, 2003.

WESTPHAL, Márcia Faria. Municípios Saudáveis Aspectos Conceituais in Revista Saúde e Sociedade v 6 n 2 p 11 Associação Paulista de Saúde Pública FSP/USP São Paulo, ago/dez 1997

\section{(cc) $\mathrm{EY}$}

Este trabalho está licenciado com uma Licença Creative Commons - Atribuição 4.0 Internacional. 